\title{
Investigation of strength conditions of the new wagon prototype type Zans
}

\author{
Pavol Š́tastniak ${ }^{1, *}$, Marián Moravčík ${ }^{2}$, and Lukáš Smetanka ${ }^{3}$ \\ ${ }^{1}$ University of Žilina, Faculty of Mechanical Engineering, Department of Transport and Handling \\ Machines, Univerzitná 8215/1, 01026 Žilina, Slovak Republic \\ ${ }^{2}$ Tatravagónka Inc., Štefánikova 887/53, 05801 Poprad, Slovak Republic \\ ${ }^{3}$ University of Žilina, Faculty of Mechanical Engineering, Department of Design and Mechanical \\ Elements, Univerzitná 8215/1, 01026 Žilina, Slovak Republic
}

\begin{abstract}
The paper describe the most significant and innovative research and development design solutions and computational procedures as part of European structural funds project. The object of our calculations is strength simulation analyzes of a new structure of railway tank wagon for transportation of ignition matters through FEM analysis created in program MSC.Marc. Results of calculations and prototype tests prove, that new structure of the construction satisfies strength assessments according to valid requirements and standards.
\end{abstract}

Keywords: strength condition analysis, tank wagon, computer tools

\section{Introduction}

In the design of freight rail vehicles follow trends that contribute to increasing the competitiveness of rail freight transport. This is not a simple matter, and it is not necessary to look at a wagon just like a regular car, but as part of a transport system in which it operates. This must correspond to the concept and design of vehicles and other equipment that are related to transport technologies.

University of Žilina and Tatravagónka Inc. Poprad jointly respond to these requirements by means of the European structural funds project with name "Development of two types of freight wagons with bogies for non-standard wheelbase or track wheelset, complying with the criteria for interoperability, environmental issues, safety and reliability", where developed, among other things, a new railway tank wagon type Zans (Fig. 1).

The vehicle of type Zans is a four-axle tank wagon with a capacity of $95 \mathrm{~m}^{3}$, for transportation of ignition matters according to RID, Class 3. The wagon is designated for transportation without limitations on all European railway tracks with normal track gauge for climatic conditions with temperatures from $-25^{\circ} \mathrm{C}$ to $+50^{\circ} \mathrm{C}$. It complies with regulations of TSI-WAG, applicable UIC Leaflets, agreement about mutual use of freight wagons in the international transport AVV (RIV), ERRI recommendations and EN standards.

\footnotetext{
* Corresponding author: pavol.stastniak@,fstroj.uniza.sk

Reviewers: Juraj Gerlici, Robert Zalewski
} 


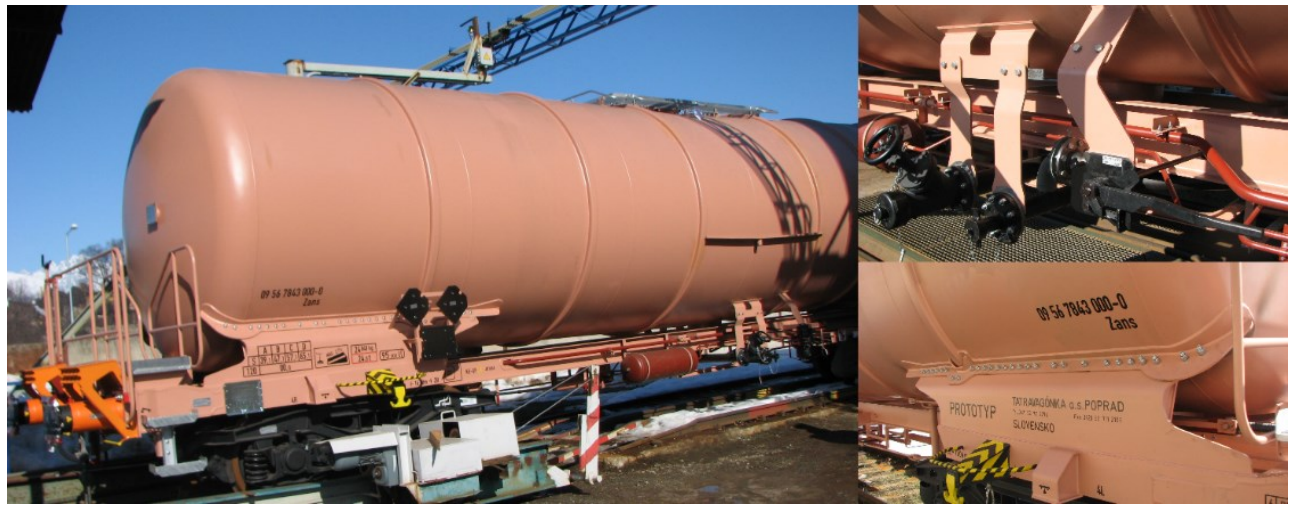

Fig. 1. The prototype of new tank wagon

The wagon is equipped with safety device against skipping the buffers type EST AC04 and "crash" buffers type EST Suprapuffer.

Filling device is installed in the upper part of the tank. Discharging from beneath through a bottom valve (mechanically controlled) and T-piece DN 100, or from the top through a rising pipe DN 80 (by means of the ball valve or TODO coupling). Wagon design enables variability of different types of valves.

In the case of tank wagons, there is considerable variability of the tank itself and its accessories, while chassis frame, brake and bogie can be more or less unified, respectively similar. Therefore, project designers have focused on the development of such a chassis frame and components, which will use several types of tanks. That means saving time and costs for static strength tests, which will also be available for other types of tank wagons.

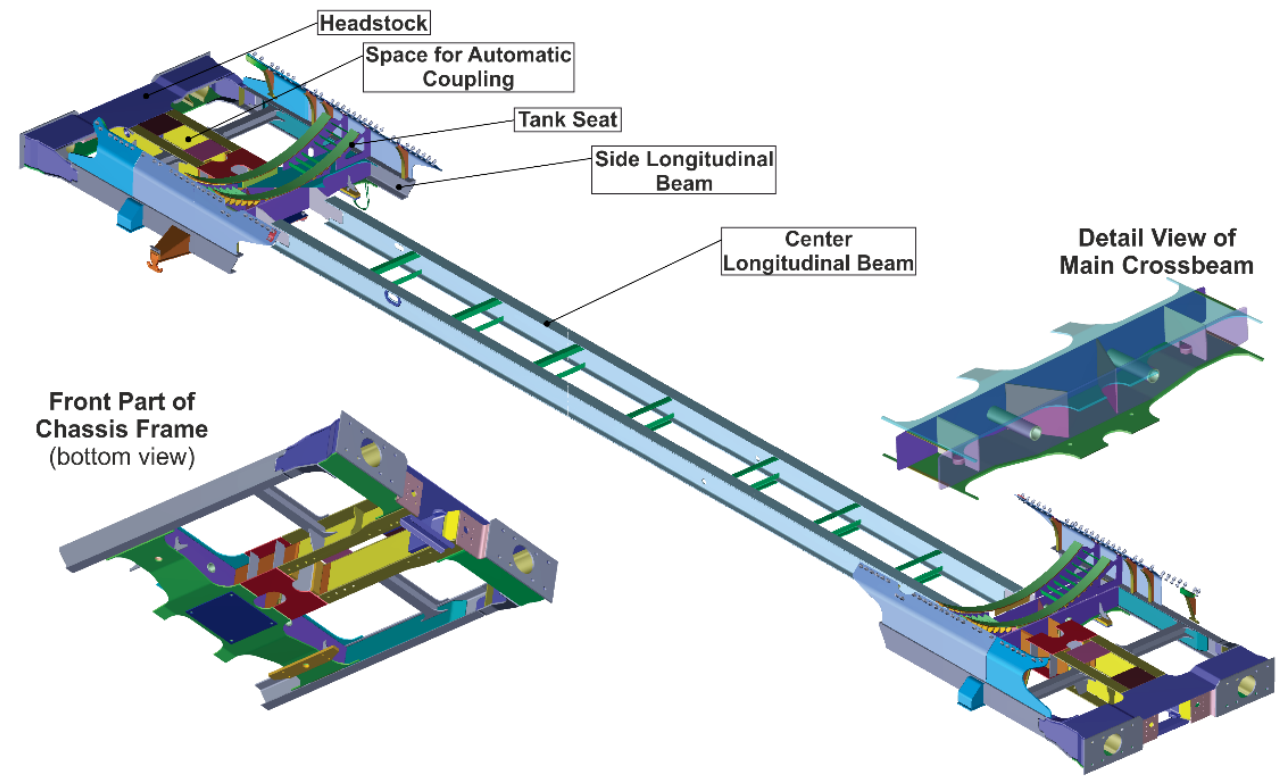

Fig. 2. Virtual model of the wagon chassis frame

The chassis frame is a welded structure made up of rolled profiles and sheets. The centre part consists of two middle longitudinal beams of the IPE profile and with them are connected side longitudinal beams of the U-profile by means of cross beams. Main cross beam has shape of box section and wagon front parts are designed to be space-suited for the installation of an 
automatic coupling with a transverse support. The chassis frame of the wagon created in design software PTC/Creo is shown in Fig. 2.

Some basic technical and dimensional parameters of the wagon are listed in Tab. 1.

Table 1. Dimensional and technical parameters of the wagon

\begin{tabular}{|l|l|}
\hline Wagon length over buffers & $16880 \mathrm{~mm}$ \\
\hline Distance between pivots & $11040 \mathrm{~mm}$ \\
\hline Tank length & $14640 \mathrm{~mm}$ \\
\hline Tank diameter & $2930 \mathrm{~mm}$ \\
\hline Weight & $25 \mathrm{t} \pm 1 \%$ \\
\hline Loading mass & $65 \mathrm{t}$ \\
\hline Tank volume & $95 \mathrm{~m}^{3}$ \\
\hline Calculation pressure & $1 \mathrm{MPa}$ \\
\hline Test overpressure & $0.3 \mathrm{MPa}$ \\
\hline Max. speed of emty wagon & $120 \mathrm{~km} / \mathrm{h}$ \\
\hline Max. speed of loaded wagon & $100 \mathrm{~km} / \mathrm{h}$ \\
\hline Temperature range & $+50^{\circ} \mathrm{C}$ to $-20^{\circ} \mathrm{C}$ \\
\hline Brake & Knorr KE-GP $(\mathrm{K})-1 \times 12^{\prime \prime}$ \\
\hline
\end{tabular}

\section{Strength assessment of wagon by means of computer simulations}

The structural design and assessment of freight wagon bodies depends on the loads they are subject to and the characteristics of the materials they are manufactured from. The loading requirements for the vehicle body structural design and assessment are based on proven experience supported by the evaluation of experimental data and published information. Where the load cases include loads that are distributed over the structure, they shall be applied in analysis and tested in a manner that represents the actual loading conditions to an accuracy commensurate with the application and the critical features of the structure.

The procedure for the validation of the mechanical strength of a wagon against the acceptance criteria shall be established on the basis of analysis (computations), laboratory static tests, laboratory fatigue tests and track tests.

Currently, by using advanced computer technology is possible those tests at high levels predict by simulation analysis. The great advantage of the mentioned simulations is that the entire development process of rolling stock is so accelerated, leading to a reduction in overall costs. Simulations and subsequent optimization of the vehicle structure is made before production of the vehicle itself. This leads to minimizing the number of unsatisfactory results conducted on a real vehicle. This may, in such a stage of development lead to delays and increased costs. Computational models of vehicles and their components are more or less simplified compared with the actual ones. This simplification is seen when comparing the results from real tests.

The object of our calculations is the strength test of new design of freight tank wagon through FEM analysis.

\subsection{Computational model}

Computational model (Fig. 3) was created in program MSC.Marc. For analysis of wagon design by finite element method has been created mesh of shell finite elements, which lies in the planes centre surfaces individual parts of analyzed design. The analysis is performed in a linear region. The distortion of the results of the analysis resulting from the introduction of the simplifications mentioned is considered negligible. For symmetry reasons of the wagon 
to his longitudinal axis, the calculations have been performed on a half model using symmetrical boundary conditions for vertical and longitudinal loading states as well as their combinations. Similarly, the half-model was used to calculate the lifting for the marked places and the lifting for one end of the wagon (lifting under headstock). For a diagonal load was created model of whole wagon.

The dimensions of the finite element mesh model are at a scale of 1:1 to the dimensions of the structure being analyzed. They are used as isoparametric, four-node shell elements with average size of elements $10 \mathrm{~mm}$. The thickness of the shell elements was determined according to the drawing documentation. Model of tank connection on rubber in cross seat was created using bulk elements of the same thickness as the rubber belt used, which are subsequently connected by means of the beams to the tank.

The boundary conditions in vertical direction have been modelled as a support at the location of the pivots, which allows rotation around all wagon axles. The model contains RBE 2 elements, that are used as a replacement for the hemispherical pivot.

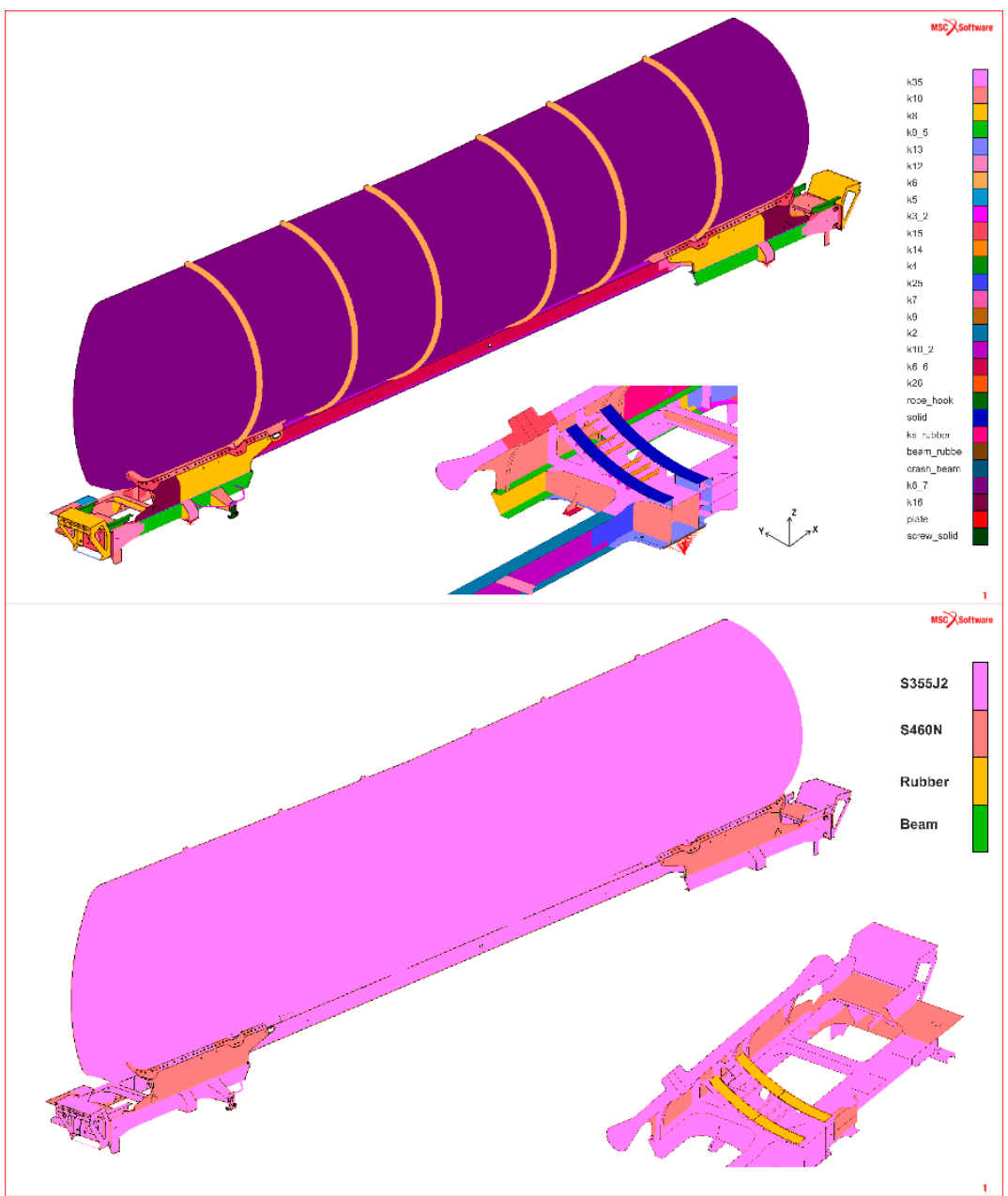

Fig. 3. Computational model - geometry (top) and materials (bottom)

Main parts of the wagon were designed from structural steel of S355J2. For parts of tank seat was used steel of S460N. Their properties, according [1], are shown in Tab. 2. 
Table 2. Properties of steels (S355J2 and S460N)

\begin{tabular}{|c|c|c|c|c|c|c|}
\hline Material & $\begin{array}{c}\text { Sheet } \\
\text { Thickness } \\
\text { [mm] }\end{array}$ & \begin{tabular}{|c} 
Min. Yield \\
Strength Re \\
[MPa]
\end{tabular} & $\begin{array}{c}\text { Min. Tensile } \\
\text { Strength Rm } \\
\text { [MPa] }\end{array}$ & $\begin{array}{c}\text { Young } \\
\text { Modulus of } \\
\text { Elasticity E } \\
{[\mathrm{MPa}]} \\
\end{array}$ & $\begin{array}{l}\text { Poisson's } \\
\text { ratio } \mu[-]\end{array}$ & $\begin{array}{r}\text { Density } \rho \\
{\left[\mathrm{kg} \cdot \mathrm{m}^{-3}\right]}\end{array}$ \\
\hline \multirow{2}{*}{ S355J2 } & 3 to 16 & 355 & 470 & \multirow{2}{*}{$2.1 \mathrm{e} 5$} & \multirow{2}{*}{0.3} & \multirow{2}{*}{7850} \\
\hline & 16 to 40 & 345 & 470 & & & \\
\hline \multirow{2}{*}{$\mathrm{S} 460 \mathrm{~N}$} & 3 to 16 & 460 & 540 & \multirow{2}{*}{$2.1 \mathrm{e} 5$} & \multirow{2}{*}{0.3} & \multirow{2}{*}{7850} \\
\hline & 16 to 40 & 440 & 540 & & & \\
\hline
\end{tabular}

Consideration is being given to the fact, that the material is linear, elastic and isotropic. Modeled rubber properties are Young modulus of elasticity $E=2 \mathrm{MPa}$ (experimentally obtained value), Poisson's ratio $\mu=0.4999$.

\subsection{Load conditions}

In reality the loads are combined in a complex manner and so it is difficult to represent them exactly in analysis. Consequently, it is generally the practice, for ease of analysis, to represent the true loads by a series of load conditions which include the above effects in a simplified form, either individually or in combination. It is essential that the simplification ensures that the effects of the true loads are not underestimated. The load conditions required for the design and assessment of the wagon will be depended on the application being considered.

The static strength requirements correspond to the exceptional load conditions under which the wagon shall remain fully functional. It shall be demonstrated by analysis and/or testing, that no permanent deformation, instability or fracture of the structure as a whole, or of any individual element, will occur under the exceptional design load conditions. It is important to ensure that the design loads are expressed in a form that is consistent with the method of analysis and the way in which the permissible material stress levels are defined.

Loading conditions, according [2], are divided into two groups:

I. Vertical operating loads where vertical load $(F z)$ is made up of the sum of the load from its own weight wagon introduced as the acceleration in the $\mathrm{z}$ direction and loads from the transported substance modelled by hydrostatic pressure acting on the walls of the tank.

II. Vertical operating loads, which is:

- load by compressive force to buffers, symmetrically on both headstocks simultaneously (P1),

- load by compressive force to buffers, at a height of $50 \mathrm{~mm}$ below the buffer axis, symmetrically on both headstocks simultaneously (P2),

- load by compressive force on the front supports of the automatic coupling (AS+),

- load by compressive force on the rear supports of the automatic coupling (AS-),

- load by compressive force to buffers, diagonally at a height of buffer axis (P3),

- load from wagon lifting on one side (ZZ2). When calculating, the lifting of the fully loaded wagon and the front bogie behind the bumpers is considered. The other side of wagon lies on the bogie,

- load from lifting of whole wagon (ZZ1). The lifting points are located in the area of the main cross beams. At the same time, both bogies are lifted with the wagon. Again, it is considered fully loaded wagon on the entire loading area including its own weight,

- combination of exceptional loads (K). In accordance with [2], it is necessary to consider a combination of vertical load with some longitudinal load. According to standard, it is also necessary to consider a combination of at least one vertical static load with compressive force on buffers, pressure and pull force for automatic coupling. Used combinations: $\mathrm{K} 1=\mathrm{P} 1+\mathrm{Fz}$ $\mathrm{K} 2=\mathrm{P} 2+\mathrm{Fz} ; \mathrm{K} 3=\mathrm{AS}++\mathrm{Fz} ; \mathrm{K} 4=\mathrm{AS}-+\mathrm{Fz}$,

- load of rope hook (TH). The design of the hook, according TSI, annex YY, must be such as 
to allow the tensile load by longitudinal force when the rope is deviated from the longitudinal axis of the wagon by 30 degrees,

- combination of vertical load and load from internal pressure, according TSI, annex YY, point YY.2.2. (FZ+pp).

\subsection{Criteria for assessment of the structure}

\subsubsection{For vertical fatigue loads}

In the meaning [3], point 4.2.2.3.3 applies, that for the majority of conventional wagon constructions, it is sufficient for the fatigue load to take into account only the loads defined in norm of EN 12663-2. The norm defines for freight wagons vertical amplitude of \pm 0.3 . Verification of fatigue cases is performed by comparing the calculated values with the values defined in EN 12663-2, annex N. In Tab. 3 are shown limits of permissible values of stress for the fatigue load cases based on [4], which are identical to annex N, norm EN 12 663-2.

Table 3. Limits of permissible values of stress for steel of S355J2

\begin{tabular}{|l|c|}
\hline \multicolumn{1}{|c|}{ Type of connection } & Allowable stress [MPa] \\
\hline A - away from weld & 273 \\
\hline B - butt weld & 150 \\
\hline C - corner joint with gusset plates & 133 \\
\hline D - corner joint and reinforcing plate & 110 \\
\hline E - welded parts carrying load & 90 \\
\hline
\end{tabular}

Some parts of the chassis frame are made from steel of S460N. Therefore, the permissible dynamic stress range for notch case A shall be calculated from the material yield strength $/ 0.2 \%$ proof stress as follows:

$$
2 \sigma_{\text {Alim }}=R_{p} \cdot 0.46
$$

Fig. 4 shows the principle for derivation of the permissible stress values. Then, according to the calculation, the allowed values of stress for steel of S460N are shown in the Tab. 4.

Table 4. Limits of permissible values of stress for steel of S460N

\begin{tabular}{|l|c|}
\hline \multicolumn{1}{|c|}{ Type of connection } & Allowable stress [MPa] \\
\hline A - away from weld & 353 \\
\hline B - butt weld & 150 \\
\hline C - corner joint with gusset plates & 133 \\
\hline D - corner joint and reinforcing plate & 110 \\
\hline E - welded parts carrying load & 90 \\
\hline
\end{tabular}



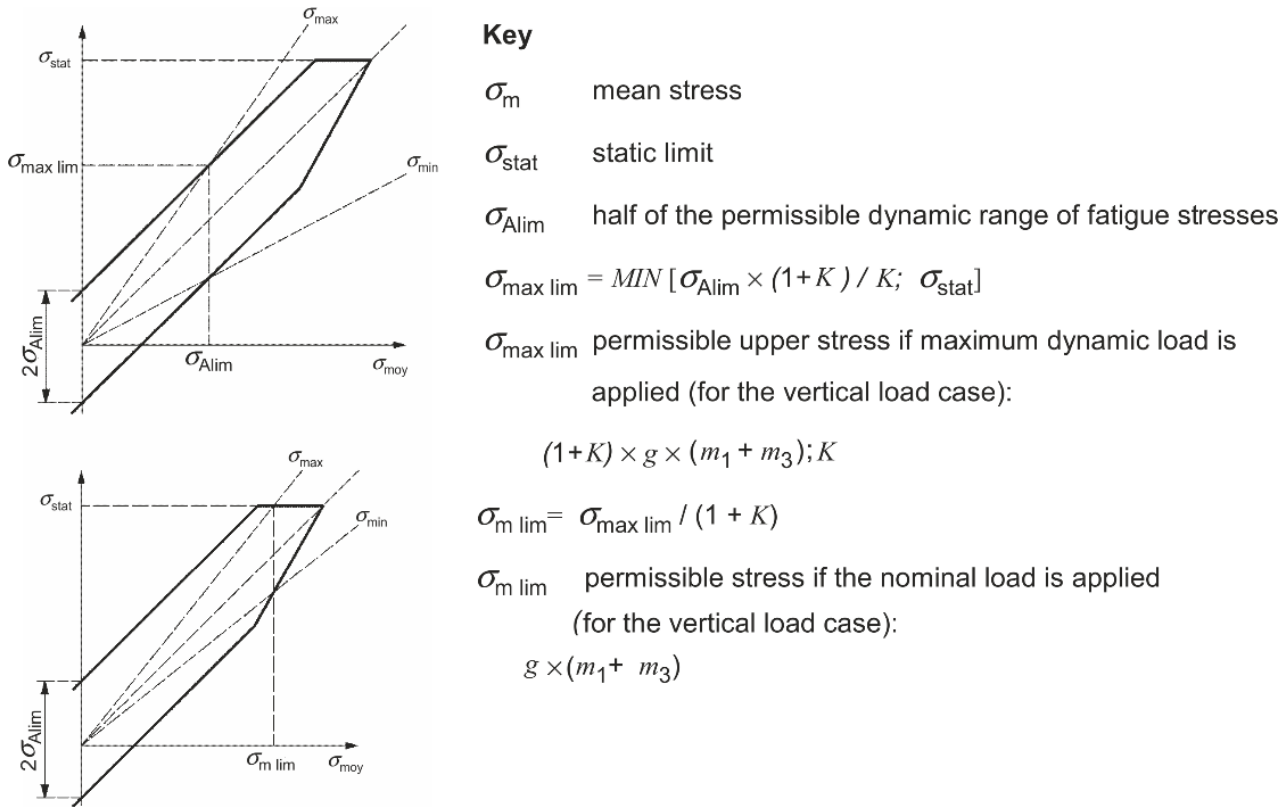
$\sigma_{\text {max } \lim }=M I N\left[\sigma_{\text {Alim }} \times(1+K) / K ; \sigma_{\text {stat }}\right]$
$\sigma_{\text {max } \lim }$ permissible upper stress if maximum dynamic load is applied (for the vertical load case):

$(1+K) \times g \times\left(m_{1}+m_{3}\right) ; K$

$\sigma_{\mathrm{m} \lim }=\sigma_{\max \lim } /(1+K)$

$\sigma_{\mathrm{m} \lim }$ permissible stress if the nominal load is applied (for the vertical load case):

$$
g \times\left(m_{1}+m_{3}\right)
$$

Fig. 4. Derivation of permissible fatigue strength values

\subsubsection{For longitudinal, combined and exceptional loads}

Longitudinal loads and their combinations with vertical loads are evaluated according to TSI 01/16-ST04CS07 WAG part 2, annex ZZ, ZZ.1. Allowed values are shown in Tab. 5.

Table 5. Material properties

\begin{tabular}{|c|c|c|c|}
\hline \multirow{2}{*}{ Mate rial } & $\begin{array}{c}\text { Sheet } \\
\text { Thickness } \\
{[\mathbf{m m}]}\end{array}$ & \multicolumn{2}{|c|}{ Min. Yield Stre ngth Re [MPa] } \\
\cline { 3 - 4 } & Basic Material & $\begin{array}{c}\text { In the Immediate } \\
\text { Vicinity of Welds }\end{array}$ \\
\hline \multirow{2}{*}{ S355J2 } & to 16 & 355 & 470 \\
\cline { 2 - 4 } & from 16 to 40 & 345 & 470 \\
\hline \multirow{2}{*}{ S460N } & to 16 & 460 & 540 \\
\cline { 2 - 4 } & from 16 to 40 & 440 & 540 \\
\hline
\end{tabular}

\subsubsection{For loads caused by lifting}

In the meaning [3], point 4.2.2.3.2.4., in the case of lifting related only to a rescue operation after derailment or another exceptional occurrence, a certain permanent deformation of the structure is allowed. For evaluation of calculations is important to know, if the yield strength was exceeded in the entire thickness of the material. Thus, in both the evaluated layers (outer layer Top and inner layer Bottom) shell elements. The criterion for deflection in the vertical direction is [3], article 2.3., i.e. the maximum deflection of the under-frame under the normal design payload shall not exceed $3 \%$ of the wheelbase or of the bogie pivot pitch from the initial position (including the effects of any counter-deflection).

\subsection{Evaluation of simulations}

The analysis is intended to detect the most critical places in the structure. We examined sizes 
of equivalent von Mises stress for all load conditions. Tab. 6 shows the comparison of the calculated stresses and allowed values on selected locations of the construction for each case of load. Behaviours of von Mises stress for selected loading cases are shown in Fig. 5 to Fig. 8.

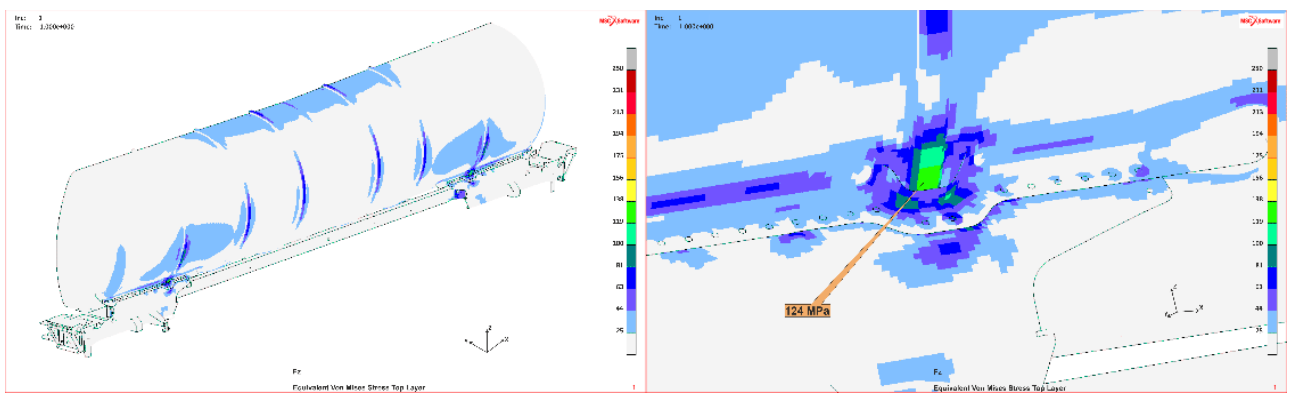

Fig. 5. Behaviour of von Mises stress - Vertical operating loads Fz

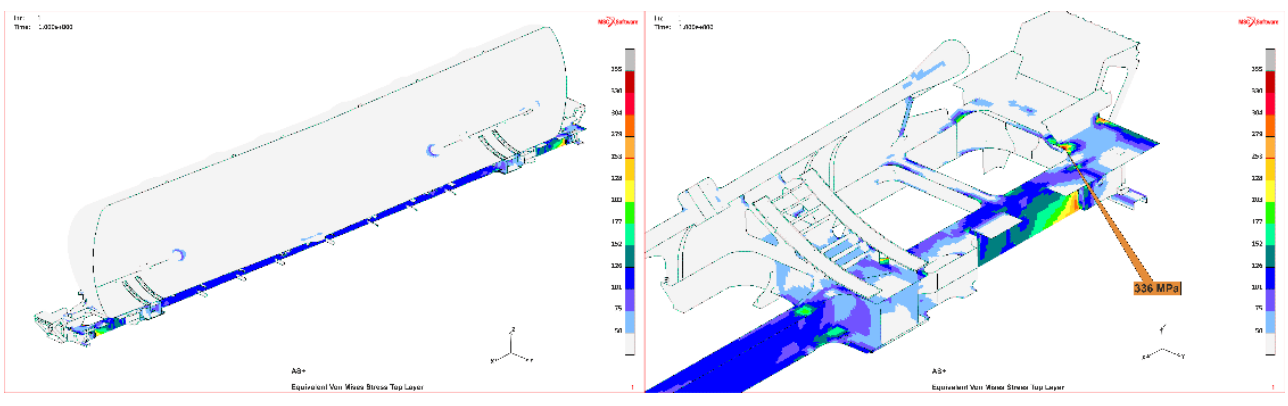

Fig. 6. Behaviour of von Mises stress - Exceptional loads AS +

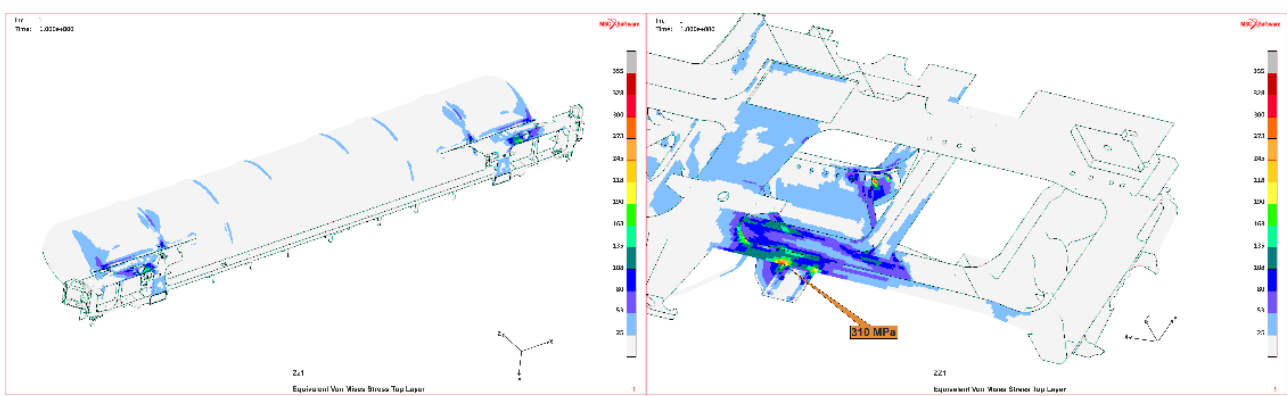

Fig. 7. Behaviour of von Mises stress - Exceptional loads ZZ1

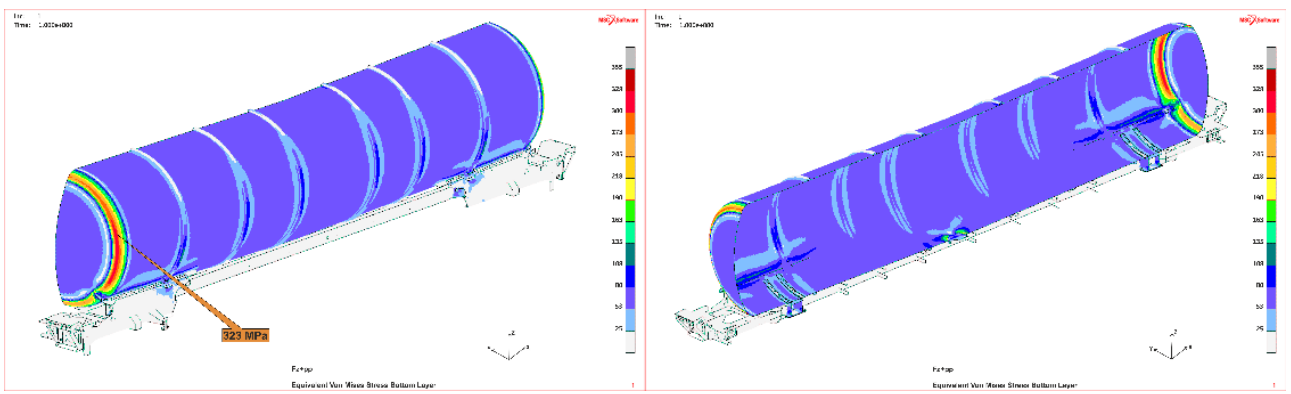

Fig. 8. Behaviour of von Mises stress - Exceptional loads Fz + pp 
Table 6. The highest values of von Mises stress and their positions

\begin{tabular}{|c|c|c|c|c|}
\hline Load Case & Selected Part of Construction & \begin{tabular}{|c|} 
von Mises \\
Stress [MPa] \\
\end{tabular} & \begin{tabular}{|c|} 
Allowable \\
Stress [MPa] \\
\end{tabular} & Safe ty Factor [-] \\
\hline \multirow{4}{*}{$\mathbf{F z}$} & Sheet of seat & 215 & 353 & 1.64 \\
\hline & Sheet of seat & 224 & 353 & 1.57 \\
\hline & Border & 102 & 110 & 1.08 \\
\hline & Ring & 124 & 273 & 2.20 \\
\hline \multirow{3}{*}{ P1 } & Sheet of seat & 331 & 460 & 1.39 \\
\hline & Lower flangeplate of headstock & 322 & 460 & 1.43 \\
\hline & Lower flangeplate of headstock & 308 & 323 & 1.05 \\
\hline $\mathbf{P 2}$ & Lower flangeplate of headstock & 340 & 460 & 1.35 \\
\hline $\mathbf{P 3}$ & Lower flangeplate of headstock & 133 & 460 & 3.46 \\
\hline AS+ & Upper flangeplate of headstock & 336 & 460 & 1.37 \\
\hline \multirow{2}{*}{ AS- } & Upper flangeplate of main cross beam & 336 & 355 & 1.06 \\
\hline & Upper flangeplate of main cross beam & 338 & 355 & 1.05 \\
\hline \multirow{3}{*}{ K1 } & Sheet of seat & 441 & 460 & 1.04 \\
\hline & Sheet of seat & 442 & 460 & 1.04 \\
\hline & Border & 334 & 355 & 1.06 \\
\hline \multirow{3}{*}{ K2 } & Sheet of seat & 442 & 460 & 1.04 \\
\hline & Sheet of seat & 446 & 460 & 1.03 \\
\hline & Border & 303 & 355 & 1.17 \\
\hline \multirow{2}{*}{$\mathbf{K 3}$} & Upper flangeplate of headstock & 317 & 460 & 1.45 \\
\hline & Upper flangeplate of headstock & 351 & 460 & 1.31 \\
\hline \multirow{3}{*}{ K4 } & Lower flangeplate of main cross beam & 331 & 355 & 1.07 \\
\hline & Sheet of seat & 427 & 460 & 1.08 \\
\hline & Sheet of seat & 425 & 460 & 1.08 \\
\hline $\mathbf{Z Z 1}$ & Carrier & 310 & 322 & 1.02 \\
\hline \multirow{2}{*}{$\mathbf{Z Z 2}$} & Sheet of seat & 385 & 460 & 1.19 \\
\hline & Sheet of seat & 411 & 460 & 1.12 \\
\hline \multirow{2}{*}{ TH } & Rope hook - upper sheet & 107 & 323 & 3.02 \\
\hline & Rope hook - lower sheet & 112 & 323 & 2.88 \\
\hline $\mathbf{F z}+\mathbf{p p}$ & Tank & 323 & 355 & 1.10 \\
\hline
\end{tabular}

\section{Conclusion}

Computational simulations are now an integral part of the development process of rolling stock. They allow a more detailed analysis of the behaviour of the vehicle as a whole or its individual parts. Therefore, it is possible to better optimize the design of rail vehicles and prevent potential problems in the operation, which would require increased costs. Chassis frames of rail vehicles are required to withstand the maximum loads consistent with their operational requirements and achieve the required service life under normal operating conditions with an adequate probability of survival.

The most unfavorable calculated vertical stress values meets the conditions according TSI 01/16-ST04CS07 WAG, part 2, annex N, N.1. Also longitudinal, combined and exceptional loads meets the conditions according TSI 01/16-ST04CS07 WAG part 2, annex ZZ, ZZ.1.

Static, fatigue and ride tests of tank wagon prototype (Fig. 9) have been performed in internationally accredited institution. The deflections of the wagon in the vertical direction were measured at the level of the longitudinal beams in five places on each side of the wagon. No residual deformation was found for repeated test loads. The deflection from the maximum vertical load did not exceed value of $3 \%$ of the bogie pivot pitch from the initial position.

During the test were detected stresses at the locations selected by institution and on the basis of client requirements. Stress values, that have been measured by strain gauges does 
not exceed the permitted levels and no residual deformations and cracks were detected.

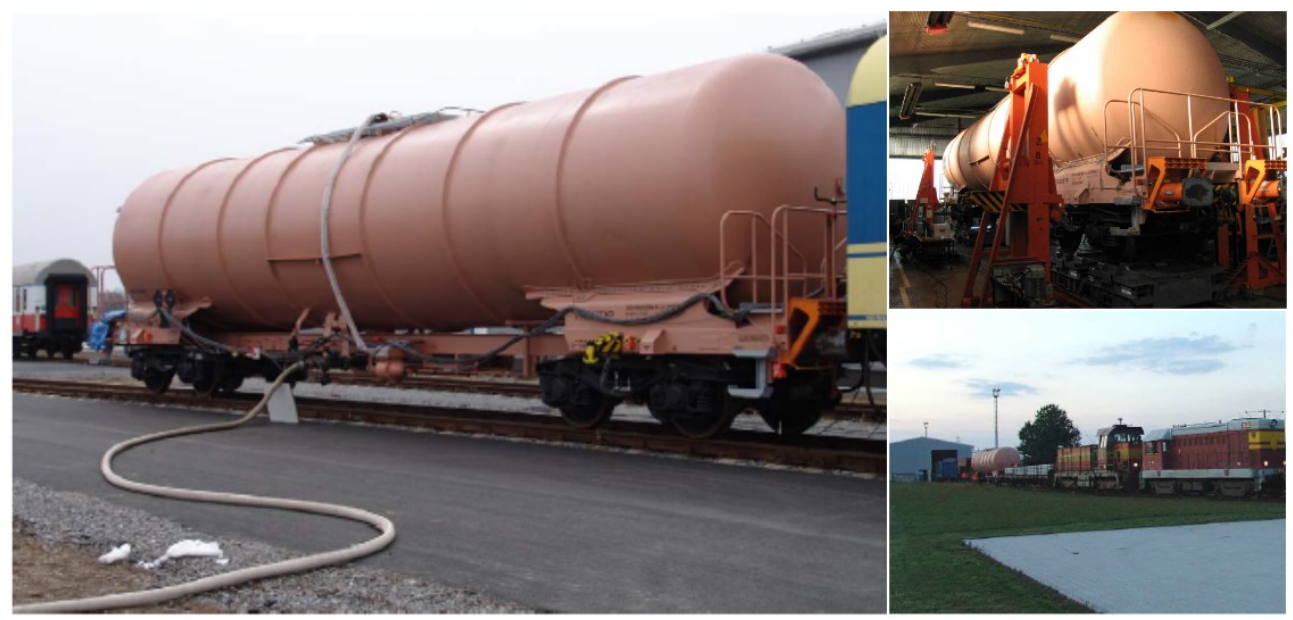

Fig. 9. Static, fatigue and ride tests of tank wagon prototype

Results of calculations and prototype tests prove, that new designed construction of the tank wagon satisfies strength conditions.

With this research and development subjects deals other publications too [5-17].

This paper was created in accordance to the processing of the project "Development of two types of freight wagons with bogies for non-standard wheelbase or track wheelset, complying with the criteria for interoperability, Environmental Issues, safety and reliability “, ITMS Code 26220220070 based on the support of Research and Development Operational Program co-financed from EU sources.

The work was supported by the Cultural and Educational Grant Agency of the Ministry of Education of the Slovak Republic in project No. KEGA 077ŽU-4/2017: Modernization of the Vehicles and engines study program. The work was also supported by the project No. APVV-0842-11: Equivalent railway operation load simulator on the roller rig and VEGA No. 1/0558/18: Research of the interaction of a braked railway wheelset and track in simulated operational conditions of a vehicle running in a track on the test stand.

Research-Educational Center of Rail Vehicles (VVCKV)

\section{References}

1. EN 10 025-3: Hot rolled products of structural steels. Part 3: Technical delivery conditions for normalized/normalized rolled weldable fine grain structural steels (2005)

2. EN 12 663-2: Railway applications. Structural requirements of railway vehicle bodies. Part 2: Freight wagons. European Committee for Standardization (2011)

3. Commission Decision 2006/861/ES (Annex J) of 28 July 2006 and Commission decision of 23 January 2009 amending Decisions 2006/861/ES and 2006/920/EC (2009/107/ES)

4. ERRI B12/RP17, No. 8: Programme of Stresses to be carried out on Wagons with Steel Underframe and Body Structure. European Rail Research Institute (1996)

5. J. Dižo, S. Steišunas, M. Blatnický, Vibration analysis of a coach with the wheel-flat due to suspension parameters changes. Procedia Engineering, 192, 107-112 (2017), ISSN $1877-7058$

6. J. Dižo, J. Harušinec, M. Blatnický, Structural analysis of a modified freight wagon bogie frame. MATEC Web of Conferences, 134 (2017), ISSN 2261-236X 
7. J. Gerlici, T. Lack, Modified HHT method for vehicle vibration analysis in time domain utilisation. Applied mechanics and materials, 486, 396-405 (2014), ISSN 1660-9336

8. J. Gerlici, T. Lack, Rail vehicles brake components test bench utilization. Applied mechanics and materials, 486, 379-386 (2014), ISSN 1660-9336

9. T. Kalina, et. al., Numerical simulation and experimental testing of two-axle chassis of low-floor trams. Manufacturing technology, 18, 2, 248-254 (2018), ISSN 1213-2489

10. V. Hauser, et. al., Impact of three axle boxes bogie to the tram behaviour when passing curved track. Procedia Engineering, 192, 295-300 (2017), ISSN 1877-7058

11. V. Hauser, et. al., Proposal of a steering mechanism for tram bogie with three axle boxes. Procedia Engineering, 192, 289-294 (2017), ISSN 1877-7058

12. S. Sapronova, et. al., Research on the safety factor against derailment of railway vehicles. EasternEuropean Journal of Enterprise Technologies, 6, 7-90, 19-25 (2017), ISSN 1729-3774

13. V. Tkachenko, S. Sapronova, I. Kulbovskyi, O. Fomin, Research into resistance to the motion of railroad undercarriages related to directing the wheelsets by a rail track. EasternEuropean Journal of Enterprise Technologies, 5, 7-89, 65-72 (2017), ISSN 17293774

14. J. Gerlici, T. Lack, J. Harušinec, Realistic simulation of railway operation on the RAILBCOT test stand. Applied mechanics and materials, 486, 387-395 (2014), ISSN 1660-9336

15. T. Lack, J. Gerlici, A modified strip method to speed up the calculation of normal stress between wheel and rail. Applied mechanics and materials, 486, 359-370 (2014), ISSN 1660-9336

16. T. Lack, J. Gerlici, A modified strip method to speed up the tangential stress between wheel and rail calculation. Applied mechanics and materials, 486, 371-378 (2014), ISSN 1660-9336

17. J. Gerlici, T. Lack, Contact geometry influence on the rail / wheel surface stress distribution. Procedia Engineering, 2, 1, 2249-2257 (2010), ISSN 1877-7058 